\title{
Acquisition of radiation- and lithium chloride-induced conditioned taste aversions in anesthetized rats
}

\author{
BERNARD M. RABIN \\ University of Maryland Baltimore County, Catonsville, Maryland \\ and \\ JOAN S. RABIN \\ Towson State University, Towson, Maryland
}

\begin{abstract}
The acquisition of a conditioned taste aversion was studied in rats exposed to ionizing radiation or given an injection of lithium chloride while anesthetized with sodium pentobarbital. Taste aversions acquired by anesthetized rats given either the radiation or lithium chloride UCS were equivalent to those acquired by unanesthetized rats. The results are interpreted as supporting the hypothesis that similar mechanisms underlie the acquisition of both radiation- and lithium chloride-induced taste aversions and that the experience of a UCS-induced illness in the awake animal is not a significant factor in conditioned taste aversion learning.
\end{abstract}

When an animal ingests a novel tasting solution, such as saccharin or sucrose, paired with an unconditioned stimulus such as lithium chloride $(\mathrm{LiCl})$ or ionizing radiation, the animal will avoid further ingestion of that solution at a subsequent presentation. This avoidance behavior, called a conditioned taste aversion (CTA), is typically acquired in a single trial. The stimulus characteristics of $\mathrm{LiCl}$ and of ionizing radiation that lead to CTA learning are not clear. In contrast to radiation, which produces no obvious behavioral signs of illness, $\mathrm{LiCl}$ is a toxic stimulus that produces an immediate overt behavioral change indicative of distress (Smith, 1971). Concordant with the observable behavioral changes following irradiation or $\mathrm{LiCl}$ injection have been the reports that rats will learn a radiationinduced CTA while anesthetized with sodium pentobarbital (Roll \& Smith, 1972), whereas they will not acquire an $\mathrm{LiCl}$-induced aversion while anesthetized (Burešova \& Bureš, 1977). One implication of these findings is that the toxic nature of the $\mathrm{LiCl}$ UCS must be experienced by the awake animal for CTA learning to occur, whereas a similar condition is not necessary for the acquisition of a radiationinduced CTA.

However, lesions of the area postrema cause a significant attenuation of the CTA produced by either irradiation or LiCl as the UCS (Ossenkopp, 1983; Rabin, Hunt, $\&$ Lee, 1983). Since the area postrema functions as the chemoreceptive trigger zone for emesis to monitor the blood and cerebrospinal fluid for potential toxins (Borison,

Address reprint requests to Bernard M. Rabin, Department of Psychology, University of Maryland Baltimore County, Catonsville, MD 21228.
1974), the similar effects of area postrema lesions would suggest that similar mechanisms lead to the acquisition of a CTA, regardless of the specific nature of the UCS. Therefore, if the LiCl-induced illness is a factor in CTA learning to that UCS, it might be expected that a possible radiation-induced illness would play a role in the acquisition of the radiation-induced CTA. If the mechanisms leading to CTA acquisition are, in fact, the same, then it could be expected that anesthesia would have similar effects on CTA learning with both stimuli.

The different effects of anesthesia on CTA learning could be due to the fact that the mechanisms by which irradiation or $\mathrm{LiCl}$ lead to the acquisiton of a CTA are different, despite the similar effects of area postrema lesions, or it could be that procedural differences between the two experiments were responsible for the different results. In the radiation experiment, Roll and Smith (1972) anesthetized the animal after it had ingested the sucrose CS but before its exposure to the radiation UCS, whereas in the $\mathrm{LiCl}$ experiment, Burešova and Bureš (1977) anesthetized the rats before passively applying the CS to the oral cavity.

Because these results have implications for understanding the nature of the UCS in taste aversion learning, as well as for CTA learning in general, the present experiment was designed to evaluate the effects of presenting either the $\mathrm{LiCl}$ UCS or the radiation UCS to anesthetized animals using the same experimental design. The procedure used was similar to that utilized by Roll and Smith (1972), who anesthetized the animals following ingestion of the CS on the conditioning day so that there would be no differences in the experimental conditions associated with CS intake between the conditioning and test days. 


\section{METHOD}

\section{Subjects}

The subjects were 46 male Sprague-Dawley-derived rats that weighed $225-250 \mathrm{~g}$ at the start of the experiment. They were maintained in individual cages in a room with a 12:12 light:dark cycle. Food and water were continually available except as required by the experimental protocol.

The subjects were divided into five groups. The first two groups served as controls for the anesthesia: one group (saline/saline, $n=9$ ) received an intraperitoneal injection of isotonic saline after ingesting the CS on the conditioning day, followed by a second injection of isotonic saline as the UCS; the second group (anesth/sham) received an ip injection of sodium pentobarbital after ingesting the sucrose $\mathrm{CS}$, followed by either sham irradiation procedures $(n=4)$ or saline injection $(n=4)$. The remaining three groups of rats served as the experimental groups: the first group (saline/LiCl, $\mathbf{n}=8$ ) received an ip injection of isotonic saline after ingesting the $\mathrm{CS}$, followed by an injection of $\mathrm{LiCl}$; the second group (anesth/rad, $\mathrm{n}=12$ ) received ip sodium pentobarbital and then radiation; and the third group (anesth/ $\mathrm{LiCl}, \mathrm{n}=9$ ) received ip pentobarbital and then $\mathrm{LiCl}$.

\section{Procedure}

After adaptation to the lab, the rats were placed on a 23.5-h waterdeprivation schedule for 10 days, during which water was available for $30 \mathrm{~min}$ a day during the early light phase of the diurnal cycle. On Days 4 and 7 of the adaptation period, the rats in the anesthesia groups were given injections of sodium pentobarbital $(30 \mathrm{mg} / \mathrm{kg}$, ip) and the rats in the saline groups were given ip injections of an equivalent volume of isotonic saline. The purpose of the pretreatment procedure was to accustom the rats to the injection procedure and to the effects of the anesthetic so that the anesthetic injection would not cause a CTA by itself.

The CTA was established using a two-bottle procedure. On the conditioning day (Day 10), all rats were presented with two calibrated drinking tubes for the 30-min drinking period: one contained tap water, and the other, $10 \%$ sucrose solution. Intake of each solution was recorded. Immediately after the drinking period, the rats were given an injection of sodium pentobarbital ( $45 \mathrm{mg} / \mathrm{kg}$, ip) or an equivalent volume of isotonic saline, as appropriate. Twenty minutes after the injection, the radiation groups were placed in a gamma irradiator and exposed to 90-100 rads, using a cesium-137 source at a fixed dose rate of $7.1 \mathrm{rad} / \mathrm{sec}$. The sham-irradiated rats were treated identically, but were not exposed to the source. The rats treated with $\mathrm{LiCl}$ were given ip injections of $3 \mathrm{mEq}$ $\mathrm{LiCl}$, and the saline-injected rats were given an equivalent-volume injection of isotonic saline. For the rats in the anesthesia groups, additional injections of pentobarbital $(30 \mathrm{mg} / \mathrm{kg}$, ip) were administered every 45-90 min to maintain the depth of anesthesia at a level at which the animals would not respond to an ear-pinch. Each time the anesthesia animals were given an injection, the saline animals were also given an equivalent injection. This procedure was carried out to maintain a deep level of anesthesia for a period of 4-7 h, after which the rats were allowed to recover from the effects of the anesthesia. On the test day (Day 11), all rats were again presented with two calibrated tubes containing tap water and $10 \%$ sucrose solution, and the intake of each was recorded.

The data are presented as preference scores: sucrose intake divided by total fluid intake. A preference score of less than 0.50 indicates less sucrose intake than water intake and, therefore, an avoidance of the normally preferred sucrose solution. For data analysis, the preference scores were transformed, using the arcsin transformation (Winer, 1962) to normalize the distributions. Since a preliminary analysis had indicated that there were no significant differences between the animals in the sham treatment group, their data were combined. Analysis of the results was performed using two-way analyses of variance with one repeated factor for the control (saline/saline and anesth/sham) and the experimental (saline $/ \mathrm{LiCl}$, anesth/rad, and anesth $/ \mathrm{LiCl}$ ) groups separately.

\section{RESULTS AND DISCUSSION}

The average conditioning-day sucrose intake measured across all groups was $20.14 \pm 0.71 \mathrm{ml}$ (mean \pm standard error). A one-way analysis of variance showed that the conditioning-day sucrose intake did not differ between the groups $[F(4,40)=1.22, p>.10]$. The preference scores are summarized in Figure 1. The comparison of the saline/saline rats with the anesthesia/sham-treated rats shows that there were no differences in sucrose preference between these groups $[F(1,15)=0.13, p>.10]$ and that the anesthesia injection by itself had no effect on test-day sucrose preference $[F(1,15)=1.04, p>.10]$. In contrast, the groups treated with $\mathrm{LiCl}$ or radiation showed a significant test-day decrease in sucrose preference relative to conditioning-day preference $[\mathrm{F}(1,52)=110.75, \mathrm{p}<.001]$, which was independent of whether the animals were injected with saline or pentobarbital $[\mathrm{F}(2,52)=0.88$, $\mathrm{p}>.10 \mathrm{]}$. In addition, the observation that the day $\times$ treatment interaction $[F(2,52)=0.36, p>.10]$ was not significant would indicate that the pattern of responding was similar across all three experimental conditions.

Overall, these results are consistent with the results obtained by Roll and Smith (1972), in showing that rats are capable of acquiring a radiation-induced CTA even when the irradiation occurs while the animals are maintained under deep surgical anesthesia. In contrast to the results obtained by Burešova and Bureš (1977), the present results also show that a CTA produced by injection of $\mathrm{LiCl}$ can also be learned while the organism is anesthetized. These differences in results are probably due to the differences in procedure. In the present study, as well as in the one by Roll and Smith (1972), the animals were not anesthetized until after the CS presentation on the conditioning day. As a result, identical states were maintained on both the conditioning and test days. Since Burešova and Bureš (1977) initally presented the CS on the conditioning day to animals that were already anesthetized and then tested for CTA learning while the animals were awake, this difference in the state of the animal may have been responsible for their failure to recall a previously acquired CTA (Rabin, Hunt, \& Lee, 1982). These results would be consistent, therefore, with the hypothesis that the acquisition of a CTA following exposure to ionizing radiation or injection of $\mathrm{LiCl}$ is mediated by similar mechanisms (Rabin et al., 1983).

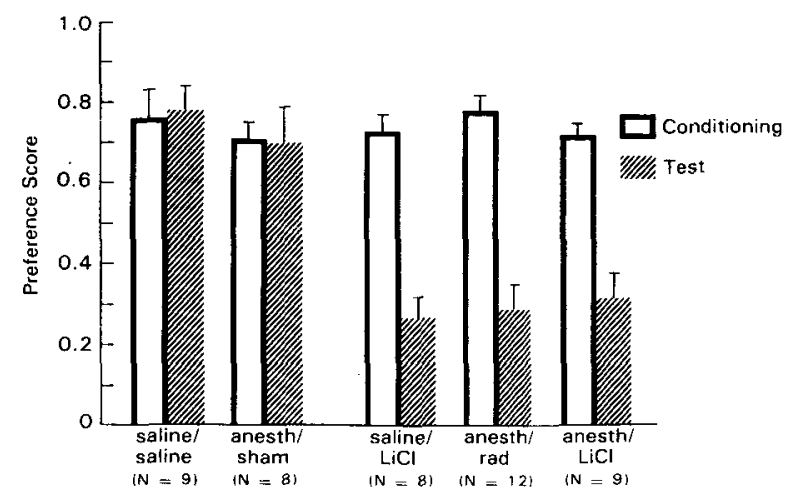

Figure 1. Sucrose preference scores of rats receiving either saline or anesthesia injections immediately after ingesting the sucrose CS on the conditioning day. 
Despite the fact that previous research has established that a stimulus-induced illness is neither a necessary nor a sufficient condition for CTA learning in awake animals (Goudie, 1979; Ionescu \& Burešova, 1977; Nachman \& Hartley, 1975), there remains a tendency to infer a relationship between the toxicity of a UCS and CTA learning when treatment with a specific UCS produces both illness and CTA learning. Since, in the present experiment, the animals were anesthetized during the presentation of the UCS, these results would strengthen the hypothesis that the experience of an $\mathrm{LiCl}$ - or radiation-induced sickness in the awake animal is not relevant for the acquisition of a CTA. It may be that the factor that the various unconditioned stimuli have in common is that they produce a discriminably novel pattern of central nervous system activity (Gamzu, 1977), or that they activate the underlying neural circuits associated with illness.

Although these results are consisent with the hypothesis that the experience of a UCS-induced illness in the awake animal is not a factor in CTA learning, there is a confounding factor that may limit this conclusion. Rozin and Ree (1972) have reported that anesthetizing rats during the CSUCS interval greatly expands the effective CS-UCS interval, so that a CTA will be acquired if the UCS is presented $9 \mathrm{~h}$ after the CS. Although that study is not directly comparable to the present one, because both the CS and the UCS were administered to awake animals, it does raise the possibility that the use of anesthesia may function to prolong the effective duration of the UCS so that the animal is able to experience the UCS upon recovery from anesthesia, particularly since peak concentrations of $\mathrm{LiCl}$ have been reported to be present in plasma 2-4 h after treatment with an oral dose (Baldessarini, 1980).

The counterargument to the suggestion that a residual UCS may have outlasted the anesthesia comes from studies of backwards conditioning using a CTA paradigm (Barker \& Smith, 1974; Smith, 1971). As a general rule, conditioning does not occur if the UCS is presented before the CS. With radiation, however, the UCS can be presented up to $6 \mathrm{~h}$ preceding the CS and still produce a CTA. This suggests that exposing an animal to a radiation UCS produces some change in the organism which is active over that period of time and which functions to produce the necessary temporal overlap between the UCS and CS. With $\mathrm{LiCl}$, to the contrary, backward conditioning does not occur, even at extremely short temporal intervals (Barker \& Smith, 1974). This suggests that the CTA-inducing stimulus properties of $\mathrm{LiCl}$ treatment are restricted to a narrow time interval directly following the injection itself. It is therefore unlikely that the animals were able to experience the CTAinducing stimulus properties of $\mathrm{LiCl}$ upon recovery from the anesthesia.

In summary, the present results show that rats are capable of acquiring either a radiation- or an $\mathrm{LiCl}$-induced CTA when the UCS is presented during anesthesia. As such, these results support the earlier findings of Roll and Smith (1972) in working with a radiation UCS, and suggest that an earlier failure to obtain such an effect with an $\mathrm{LiCl}$ UCS (Burešova \& Bureš, 1977) was due to procedural differences. The present results are also consistent with the hypothesis that similar mechanisms mediate the acquisition of a CTA following treatment with ionizing radiation or with injection of $\mathrm{LiCl}$. In addition, these results provide additional experimental support for the several theories that propose that a UCS-induced illness is not the proximal stimulus leading to the acquisiton of a CTA.

\section{REFERENCES}

BALDESSARINI, R. J. (1980). Drugs and the treatment of psychiatric disorders. In A. G. Gilman, L. S. Goodman, \& A. Gilman (Eds.), Goodman and Gilman's The pharmacological basis of therapeutics (6th ed.). New York: Macmillan.

BARKER, L. M., \& SMITH, J. C. (1974). A comparison of taste aversions induced by radiation and lithium chloride in CS-US and US-CS paradigms. Journal of Comparative and Physiological Psychology, 87, 644-654.

Borison, H. L. (1974). Area postrema: Chemoreceptive trigger zone for vomiting-is that all? Life Sciences, 14, 1807-1817.

Burešova, O., \& BurEš, J. (1977). The effect of anesthesia on acquisition and extinction of conditioned taste aversion. Behavioral Biology, 20, $41-50$.

GAMzU, E. (1977). The multifaceted nature of the post ingestional consequence-Is there a single common factor? In L. M. Barker, $M$. R. Best, \& Domjan (Eds.), Learning mechanisms in food selection. Waco, TX: Baylor University Press.

GounIE, A. J. (1979). Aversive stimulus properties of drugs. Neuropharmacology, 18, 971-979.

IONESCU, E., \& Burešova, O. (1977). Failure to elicit conditioned taste aversion by severe poisoning. Pharmacology, Biochemistry and Behavior, 6, 251-254.

NACHMAN, M., \& HARTley, P. L. (1975). Role of illness in producing learned taste aversion in rats: A comparison of several rodenticides. Journal of Comparative and Physiological Psychology, 89, 1010-1018.

OSSENKOPP, K.-P. (1983). Taste aversions conditioned with gamma radiation: Attenuation by area postrema lesions in rats. Behavioural Brain Research, 7, 297-305.

RABIN, B. M., Hunt, W. A., \& LEe, J. (1982). State-dependent interactions in the antihistamine-induced disruption of a radiation-induced taste aversion. Radiation Research, 90, 621-627.

RABin, B. M., HUNT, W. A., \& LEE, J. (1983). Attenuation of radiationand drug-induced conditioned taste aversions following area postrema lesions in the rat. Radiation Research, 93, 388-394.

Roll, D. L., \& SMITH, J. C. (1972). Conditioned taste aversion in anesthetized rats. In M. E. P. Seligman \& J. L. Hager (Eds.), Biological foundations of learning. New York: Appleton-Century-Crofts.

RozIN, P., \& REE, P. (1972). Long extension of effective CS-US interval by anesthesia between CS and US. Journal of Comparative and Physiological Psychology, 80, 43-48.

Smith, J. C. (1971). Radiation: Its detection and its effects on taste preferences. In E. Stellar \& J. M. Sprague (Eds.), Progress in physiological psychology (Vol. 4). New York: Academic Press.

WINER, B. J. (1962). Statistical principles in experimental design. New York: McGraw-Hill.

(Manuscript received February 23, 1984; revision accepted for publication April 25, 1984.) 